\title{
Microstructure and Mechanical Properties of as Cast Aluminium Alloy 7075/Basalt Dispersed Metal Matrix Composites
}

\author{
S. Ezhil Vannan*, S. Paul Vizhian \\ Department of Mechanical Engineering, University Visveswarya College of Engineering Affiliated to Bangalore \\ University, Bangalore, India \\ Email: ${ }^{*}$ ezhilsil@yahoo.co.in
}

Received 26 January 2014; revised 28 February 2014; accepted 10 March 2014

Copyright (C) 2014 by authors and Scientific Research Publishing Inc.

This work is licensed under the Creative Commons Attribution International License (CC BY).

http://creativecommons.org/licenses/by/4.0/

(c) (i)

\begin{abstract}
This paper aims to study the effects of short basalt fiber reinforcement on the mechanical properties of cast aluminium alloy $\mathbf{7 0 7 5}$ composites containing short basalt fiber of content ranging from 2.5 to 10 percent by weight in steps of 2.5 percent and fabricated using compo-casting technique. The objective is to investigate the process feasibility and resulting material properties such as young's modulus, ductility, hardness \& compression strength. The properties obtained are compared with those of as-cast that were manufactured under the same fabrication conditions. The results of this study revealed that, as the short basalt fiber content was increased, there were significant increases in the ultimate tensile strength, hardness, compressive strength and Young's modulus, accompanied by a reduction in its ductility. Furthermore, the microstructure $\&$ facture studies were carried out using Optical Microscopy (OM) and Scanning Electron Microscopy (SEM) in order to establish relationships between the quality of the fiber/aluminium interface bond and hence to link with mechanical properties of the composites.
\end{abstract}

\section{Keywords}

Metal Matrix Composite (MMCs), Aluminium Alloy, Basalt Fibers, Mechanical Properties

\section{Introduction}

Metal Matrix Composites (MMCs) like most composite materials, provide significantly enhanced properties over conventional monolithic materials, such as higher strength, stiffness, and weight savings [1]-[4]. Metal matrix composites are used in a wide range of high performance applications today. The usage of MMCs was over

"Corresponding author.

How to cite this paper: Vannan, S.E. and Vizhian, S.P. (2014) Microstructure and Mechanical Properties of as Cast Aluminium Alloy 7075/Basalt Dispersed Metal Matrix Composites. Journal of Minerals and Materials Characterization and Engineering, 2, 182-193. http://dx.doi.org/10.4236/jmmce.2014.23023 
5.5 million kg in the year 2006 and is increasing at an annual growth rate of over 8\% [5]. Most of their current applications are in aviation, ground transportation, electronics and sports industries. The applications of metal matrix composites in aeronautics have been established in the aerostructural, aeropropulsion and subsystem categories. The Aluminium alloys are quite attractive due to their low density, their capability to be strengthened by precipitation, their good corrosion resistance, high thermal and electrical conductivity, and their high damping capacity [6]. The strong demand for weight reduction in car and aircraft fabrication urges the optimization of the design of products employing low weight materials [7]. The replacement of conventional materials by lighter metals such as Aluminium alloys is, therefore, highly desirable. However, Aluminium alloys are not sufficiently stiff or strong for many purposes and their reinforcement is necessary. Aluminium based MMCs are outstanding candidates for these applications owing to the high ductility of the matrix and the high strength of the hard reinforcing phases. The attraction for such materials is also due to the very high specific modulus, strength to weight ratio, fatigue strength and wear resistance [8]-[10]. The presence of reinforcing particles produces potential properties non-attainable by other materials [11]. The reinforcement metal matrix offer potential for improvement in efficiency, mechanical performance and reliability over the new generation alloys [12]-[14]. The introduction of a ceramic material into a metal matrix produces a composite material that results in an attractive combination of physical and mechanical properties which cannot be obtained with monolithic alloys. There is an increasing need for knowledge about the processing techniques and mechanical behaviour of fiber reinforced MMCs in view of their rising production volumes and their wider commercial applications. Composites have been developed with greater success by the use of fiber reinforcements in metallic materials [15]. Earlier study on MMCs addressed the behavior of continuous fiber reinforcement composite based on aluminum, zinc and titanium alloys matrices and the reinforcements used was Alumina fibers, carbon fiber, glass fiber etc.

In recent years, considerable work has been done on fiber reinforced metal matrix composites which exhibit low friction, low wear rate and excellent antiseizing properties. composite fiber reinforced metal matrices possess great potential to be the next generation of advanced composites offering many advantages compared to fiber reinforced polymers. Specific advantages include high temperature capability, superior environmental stability, better transverse, shear and fatigue properties [16] [17]. Fiber reinforced composites are often characterized by their high specific strength and specific modulus parameters (i.e., strength to weight ratios), and are widely used for applications in low weight components [18]. Metals reinforced by short-fiber, have the advantage of being machinable and workable using conventional processing techniques, especially short fiber reinforcements have more favorable influence on the stiffness and elastic-plastic tensile properties. If good fiber alignment is obtained the tensile properties are much improved [19]. Fiber alignment is often obtained during processing by using either contracting flow or expanding flow in the extrusion. The mechanism of strengthening and the mechanical properties of metal matrix composites have attracted a considerable number of investigations [20]-[23]. Very little literature is available on mechanical properties of fiber reinforced metal matrix composites. Most of the published data pertain to the mechanical properties of particulate-reinforced MMCs deal with tensile properties while only a relatively small amount of data has been obtained dealing with compression properties, although it is generally known that the compressive strength of an MMC is invariably higher than its UTS. Hence, in the present investigation, importance is also given to the compressive properties of the MMCs, together with the tensile properties such as the UTS, ductility, hardness and Young's modulus. The mechanical properties of MMCs are also affected by the residual stresses, which form as a result of the differences in the thermal expansion coefficients between the matrix and reinforcement. There are various models, which have been developed to estimate the residual stresses in MMCs. For instance, the models developed by Eshelby [24], Mura and Taya [25] and Tanaka and Mori [26] can be utilized to predict the yield stress both in tension as well as compression terms.

Analysis of the theoretical model proposed by Eshelby [24] in combination with X-ray diffractrometry studies conducted by Arsenault and Taya [27] reveals some interesting trends. First, the theoretical model predicts yield stress, which is higher in compression than in tension, this is in agreement with experimental results. Second, the predicted values of the yield stress of the MMCs were found to be less than those experimentally determined both in tension and compression. This discrepancy was attributed to the high dislocation density present in the annealed MMCs, and which is not considered in the development of the models. Third, although the average residual stress in the MMCs is relatively small, there can be relatively substantial compressive stress at the matrix-reinforcement interface. In addition, the state of stress in the matrix region adjacent to the reinforcement 
may be either tensile or compressive, depending on the size, distribution and loading of the strengthening phases. Fourth, in the matrix region between the reinforcements, the residual stress will be tensile and plastic deformation is likely to initiate in this since it contains fewer dislocations when compared to the reinforcement-matrix interface.

In the present investigation, aluminium alloy $\mathrm{Al} 7075$ was used as the matrix material. Al 7075 alloy has the highest strength and ductility of the aluminium alloys with excellent machinability and good bearing and wear properties [28]. Most of the fiber reinforced metal matrix composites are produced by liquid metallurgy, sometimes known as the "vortex method" [29], although many different processes for fabricating these as cast composites are also available which have been reported by various researchers. In the present work, the "vortex method" of producing AMC's, in which basalt short fiber have been used as the candidate reinforcements of fiber sizes ranging from 1 to $1.5 \mathrm{~mm}$ and added to the vortex formed in the $\mathrm{Al} 7075$ melt above its liquidus temperature. Since the ductility, ultimate tensile strength (UTS), compressive strength, Young's modulus and hardness of the composite material are all vital properties of a structural material, the present investigation aims at studying these properties in the $\mathrm{Al} 7075$ alloy/basalt fiber composites.

\section{Experimental}

\subsection{Materials}

In the present study, Al 7075 alloy having the chemical composition as per the ASTM ingot specification given in Table 1 was used as the base matrix alloy. Basalt short fibers were used as reinforcement. The weight percentage of basalt short fiber was varied from $2.5 \%$ - $10 \%$ steps of $2.5 \mathrm{wt} \%$. The compocasting technique was used to prepare the composite specimens, which is similar to the one used by Sharma et al. [30].

\subsection{Preparation of Composite}

In this process, the cu coated basalt short fiber was first pre-heated to temperature of $500^{\circ} \mathrm{C}$ and maintained at that temperature till it was introduced into the $\mathrm{Al}$ alloying elements melt. The preheating of the reinforcement is necessary in order to reduce the temperature gradient and to improve wetting between the molten metal and the basalt short fiber. A known quantities of these metals ingots were pickled in $10 \% \mathrm{NaOH}$ solution at room temperature for ten minutes. Pickling was done to remove the surface impurities. The smut formed was removed by immersing the ingots for one minute in a mixture of 1 part nitric acid and 1 part water followed by washing in methanol. These cleaned ingots after drying in air were loaded into different alumina crucibles. These crucibles kept in different furnace, which were setting metals respected melting temperature. The melts were super heated and maintained at that temperature. The temperatures were recorded using a chromel-alumel thermocouple. The molten metals were then degassed using purified nitrogen gas. Purification process with commercially pure nitrogen was carried out by passing the gas through an assembly of chemicals arranged in a row (concentrated sulphuric acid and anhydrous calcium chloride, etc.) at the rate of $1000 \mathrm{cc} /$ minute for about 8 minutes. A stainless steel impeller or stirrer coated with basalt short fiber was used to stir the molten metal and create a vortex. The impeller used for stirring was of centrifugal type with three blades welded at $45^{\circ}$ inclination and $120^{\circ}$ apart. The stirrer was rotated at a speed of $500 \mathrm{rpm}$ and a vortex was created in the melt. The depth of immersion of the impeller was approximately one third the height of the molten metal above the bottom of the crucible. The reinforcing basalt short fiber, which were preheated in the muffle furnace, were introduced into the vortex at the rate of $120 \mathrm{gm} / \mathrm{min}$. Stirring was continued until interface interactions between the basalt short fiber and the matrix promoted wetting. Then the melt was degassed using pure nitrogen for about 3 - 4 minutes and after reheat-

Table 1. Chemical composition of Al 7075 alloy and basalt fiber.

\begin{tabular}{cccccccccc}
\hline Element & $\mathrm{Si}$ & $\mathrm{Fe}$ & $\mathrm{Cu}$ & $\mathrm{Mn}$ & $\mathrm{Mg}$ & $\mathrm{Cr}$ & $\mathrm{Zn}$ & $\mathrm{Ti}$ & $\mathrm{Al}$ \\
\hline$\%$ & 0.4 & 0.5 & 1.6 & 0.3 & 2.5 & 0.15 & 5.5 & 0.2 & $\mathrm{Bal}$ \\
Element & $\mathrm{SiO}_{2}$ & $\mathrm{Al}_{2} \mathrm{O}_{3}$ & $\mathrm{Fe}_{2} \mathrm{O}_{3}$ & $\mathrm{MgO}$ & $\mathrm{CaO}$ & $\mathrm{Na}_{2} \mathrm{O}$ & $\mathrm{K}_{2} \mathrm{O}$ & $\mathrm{TiO}_{2}$ & $\mathrm{MnO}$ \\
$\%$ & 69.51 & 14.18 & 3.92 & 2.41 & 5.62 & 2.74 & 1.01 & 0.55 & 0.04 \\
\hline
\end{tabular}


ing to super heat temperature $\left(540^{\circ} \mathrm{C}\right)$, it was poured into the pre heated lower half die of the hydraulic press. The top die was brought down to solidify the composite by applying a pressure of $100 \mathrm{~kg} / \mathrm{sq} . \mathrm{cm}$. Both the lower die and the upper dies were preheated to $280^{\circ} \mathrm{C}$, before the melt was poured into it. The pressure applied enables uniform distribution of the basalt short fiber in the developed composite.

\subsection{Testing of Specimens}

All tests were conducted in accordance with ASTM standards. Tensile tests were conducted at room temperature using a universal testing machine (UTM) in accordance with ASTM Standard E 8-82. The tensile specimens of diameter $8.0 \mathrm{~mm}$ and gauge length $75 \mathrm{~mm}$ were machined from the cast composites with the gauge length of the specimens parallel to the longitudinal axis of the castings. For each composite, four tensile test specimens were tested and the average values of the UTS, Young's modulus and ductility (in terms of percentage elongation) were measured. The hardness tests were conducted in accordance with ASTM Standard E 10 using a Brinell hardness tester with a ball indenter of $2.5 \mathrm{~mm}$ diameter and a load of $31.25 \mathrm{~kg}$. The load was applied for 30 secs. Eight hardness readings were taken for each specimen at different locations to circumvent the possible effects of particle segregation. Compression tests were conducted on a UTM in accordance with ASTM Standard E 9 at room temperature. In this test the compression loads were gradually increased and the corresponding strain was measured until the specimen failed. Each result is an average of four readings. The results are tabulated in Table 2.

\section{Results and Discussion}

\subsection{Microstructure}

The micrograph illustrating the microstructure of the metal matrix composites was used in this investigation. Samples for the microscopic examination were prepared by standard.

Metallographic procedures etched with killer's agent and examined under optical microscope. The optical microstructure of as-cast Al 7075 alloy and Al 7075/short basalt fiber composite are shown in Figures 1(a)-(c). Micrograph indicates the nearly uniform distribution of the short basalt fiber in the Al/7.5\% basalt short fiber \& $\mathrm{Al} / 10 \%$ basalt short composite.

The feasibility by compo-casting to produce Al-based composite containing basalt short fiber was confirmed, the incorporation of basalt short fiber in the Al matrix was successful in all the castings. Figures 1(a)-(c) show the microstructure of a) as cast $\mathrm{Al} 7075$ alloy, b) $\mathrm{Al} / 7.5$ percent basalt short fiber reinforced MMCs and c) $\mathrm{Al} / 10$ percent basalt short fiber-reinforced composites. Visual examination shows that the feasibility by liquid metallurgy to produce $\mathrm{Al}$-based composite containing basalt short fiber was confirmed, and the incorporation of basalt short fiber in the $\mathrm{Al}$ matrix was successful in all the castings. Microstructural analyses of the as cast $\mathrm{Al} 7075$ alloy and basalt short fiber-reinforced composite showed large grain size of the Al 7075 alloy matrix and a quite non-homogeneous distribution of the reinforcing fibers. Spheroidal grains observed are due to casting limiting dendrite formation and growth. This is due to overlapping solute diffusion fields, which homogenizes solute gradients and prevents constitutional super cooling. This leads to spheroidal grains. The grain size of matrix is reduced by great extent in all the $\mathrm{Al} /$ basalt short fiber composite prepared in this study under different experimental conditions (125 $\mu \mathrm{m}$ to $45 \mu \mathrm{m}$ ). The physical properties depend on the microstructure and particle size, shape and distribution in the matrix alloy. The grain size of matrix alloy is somewhat larger than that of the

Table 2. Mechanical properties of as cast Al 7075/basalt dispersed metal matrix composites containing varying amounts of basalt fiber.

\begin{tabular}{cccccc}
\hline $\begin{array}{c}\text { Basalt fiber } \\
\text { content (\%) }\end{array}$ & $\begin{array}{c}\text { UTS } \\
\text { (MPa) }\end{array}$ & $\begin{array}{c}\text { Brinell hardness } \\
\text { (BHN) }\end{array}$ & $\begin{array}{c}\text { Young's modulus } \\
\text { (GPA) }\end{array}$ & $\begin{array}{c}\text { Ductility } \\
\text { (\% elongation) }\end{array}$ & $\begin{array}{c}\text { Ultimate compression } \\
\text { strength (MPa) }\end{array}$ \\
\hline 0 & 129 & 65 & 76 & 15 & 242 \\
2.5 & 153 & 71 & 79 & 10.15 & 271 \\
5.0 & 169 & 73.6 & 84 & 9.38 & 320 \\
7.5 & 175 & 77.7 & 85 & 9 & 331 \\
10 & 179 & 77.2 & 87 & 8.5 & 342 \\
\hline
\end{tabular}




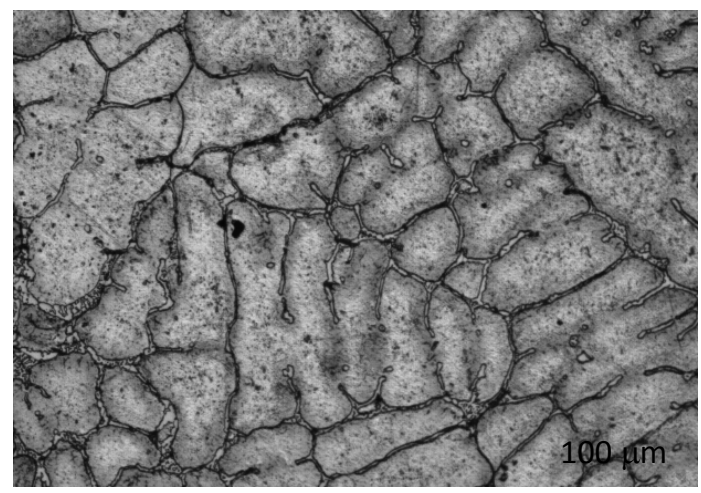

(a)

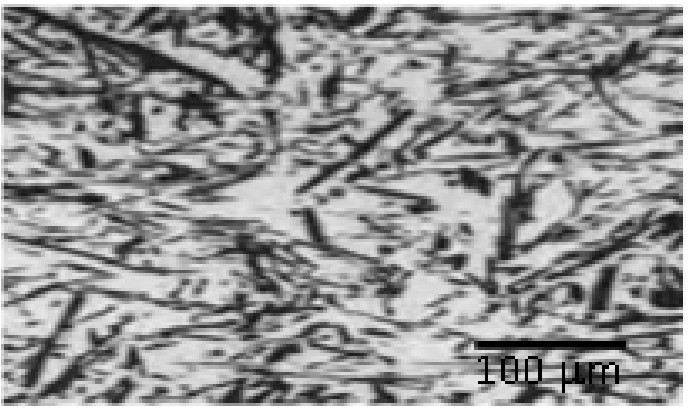

(b)

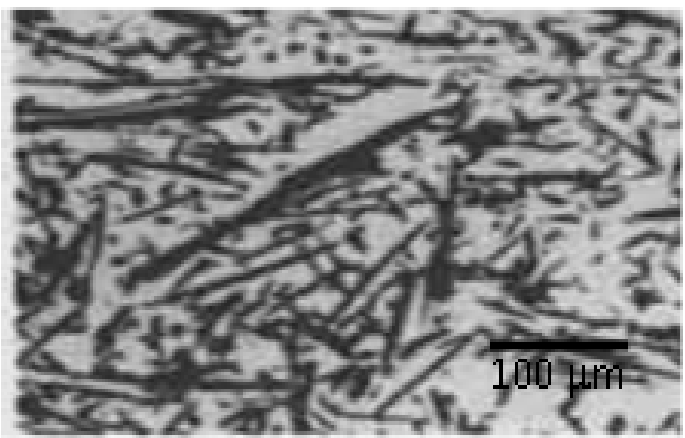

(c)

Figure 1. The microstructure of the (a) Al matrix alloy (b) $\mathrm{Al} / 7.5 \%$ basalt short fiber MMCs and (c) $\mathrm{Al} / 10 \%$ basalt short fiber MMCs.

composites. There were large clusters of basalt short fiber within some areas of the matrix while other areas were entirely basalt short fiber depleted. The reinforcement of basalt short fiber led to an evident grain refinement, improve mechanical, damping, thermal, corrosion, tribological and wear properties.

\subsection{Elastic Modulus}

The plot of young's modulus with a variation of basalt dispersoid in metal matrix composite has been presented in Figure 2. The measured mean values of elastic moduli were plotted as a function of weight percentage of basalt short fiber. From the study it can be observed that within the scope of this investigation as the short basalt fiber content was increased, there has been an increase in the young's modulus. The variation in the young's modulus value expressed as percentage when compared with young's modulus value of aluminium alloy 7075 conforming to without any basalt fiber addition has been computed and tabulated in Table 1. It can be observed that up to $2.5 \%$ of dispersed basalt fiber addition there has been an increase of $3.59 \%$ in the young's modulus 


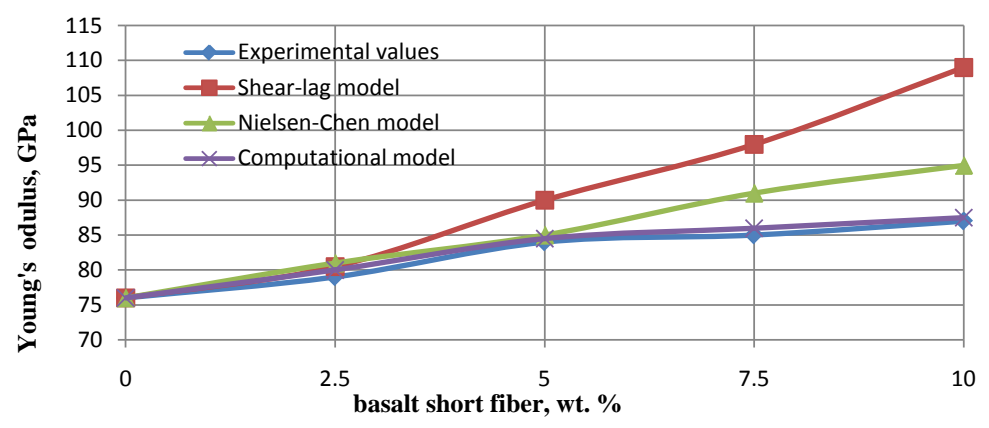

Figure 2. Typical comparison of experimental and theoretical values of Young's modulus for as cast $\mathrm{Al} 7075$ alloy/basalt dispersed metal matrix composites.

value. With further increase in addition of short basalt fiber, there has been relative higher increase in the young's modulus value and when short fiber content was $10 \%$ by wt., there has been an improvement of $14.47 \%$ in Young's modulus value. The increase in Young's modulus may be due to the alignment of these basalt short fibers parallel to the axis with minimum segregation in the alloys. McDanels [31] is of the opinion that the elastic modulus increases with increase in reinforcement content. However, elastic modulus has been found to be independent of the type of reinforcement. There are many micromechanical models available in the literature for the prediction of theoretical value of young's modulus for composite. In the present investigation three models namely, shear lag model, Neilsen-chen model \& computational model have been used for comparison of theoretical value with experimental value. The theoretical values computed by three models are presented in the Table 3. The Young's modulus value predicted theoretically for various percentage of dispersoid basalt fiber have been superimposed in the Figure 2 for the sake of comparison. It can be observed that the trend of the theoretical results predicted by adopting micromechanical models by earlier investigators available in the literature is similar to the trend value obtained in this investigation.

\subsection{Tensile Properties}

The plot of Ultimate Tensile Strength (UTS) with a variation of basalt dispersoid in metal matrix composite has been presented in Figure 3. The measured mean values of UTS were plotted as a function of weight percentage of basalt short fiber. From the study it can be observed that within the scope of this investigation as the short basalt fiber content was increased, there has been an increase in the UTS. The variation in the UTS value expressed as percentage when compared with young's modulus value of aluminium alloy 7075 conforming to without any basalt fiber addition has been computed and tabulated in Table 4. It can be observed that up to 2.5\% of dispersed basalt fiber addition there has been an increase of $18.60 \%$ in the young's modulus value. With further increase in addition of short basalt fiber, there has been relative higher increase in the UTS value and when short fiber content was $10 \%$ by wt., there has been an improvement of $38.75 \%$ in UTS value. There has been increase in tensile strength of the composites beyond $5 \mathrm{wt} \%$ basalt short fiber is attributed due to proper bonding between the matrix and reinforcement materials. Finer the grain size better is the hardness and strength of composites leading to lowering of wear rates. The increase in UTS is attributed to the presence of hard basalt short fiber, which imparts strength to the matrix alloy, thereby providing enhanced tensile strength. Vogelsangs' et al. [32] believes that the improvement in UTS may be due to the matrix strengthening. The reasons assigned are reduction in the alloy grain size and generation of a high dislocation density in the matrix, which is a result of the difference in thermal expansion between the metal matrix and the basalt short fiber reinforcement. There are many micromechanical models available in the literature for the prediction of theoretical value of UTS for composite. In the present investigation two models namely, Miwa model \& modified model have been used for comparison of theoretical value with experimental value. The theoretical values computed by two models are presented in the Table 4. The UTS value predicted theoretically for various percentage of dispersoid basalt fiber have been superimposed in the Figure 3 for the sake of comparison. It can be observed that the trend of the theoretical results predicted by adopting micromechanical models by earlier investigators available in the literature is similar to the trend value obtained in this investigation. 


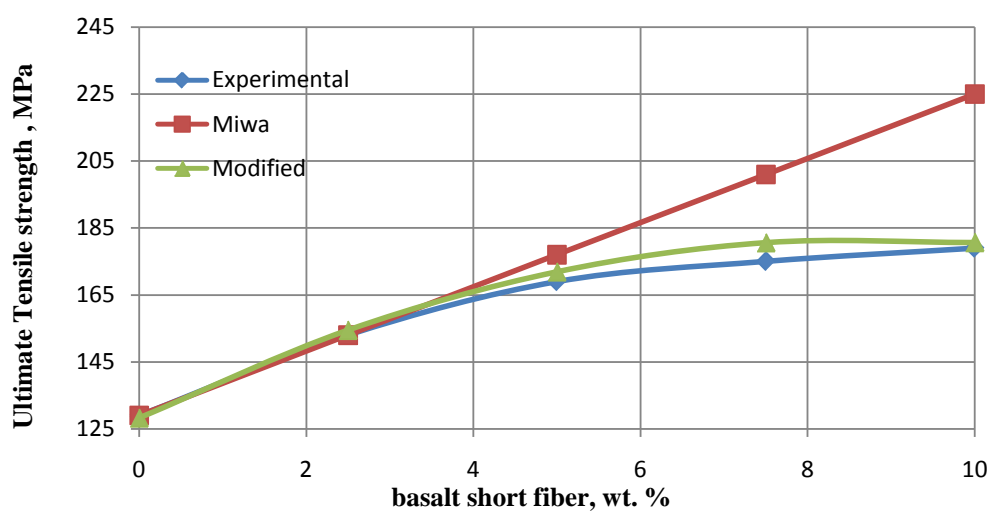

Figure 3. Typical comparison of the experimental and the theoretical UTS values for $\mathrm{Al}$ alloy/basalt dispersed metal matrix composites.

Table 3. Comparison of experimental and theoretical values of Young's modulus for as cast $\mathrm{Al}$ 7075/basalt dispersed metal matrix composite.

\begin{tabular}{|c|c|c|c|c|c|c|}
\hline \multirow{2}{*}{ Sl. No } & \multirow{2}{*}{$\begin{array}{c}\text { Dispersoid } \\
\text { basalt short } \\
\text { fiber content (\%) }\end{array}$} & \multirow{2}{*}{$\begin{array}{l}\text { Experimental } \\
\text { Young’s modulus } \\
\text { GPa }\end{array}$} & \multicolumn{3}{|c|}{ Theoretical Young's modulus GPa } & \multirow{2}{*}{$\begin{array}{l}\text { Variation in the } \\
\text { Young's modulus } \\
\text { value (\%) }\end{array}$} \\
\hline & & & $\begin{array}{c}\text { Shear-lag } \\
\text { model }\end{array}$ & $\begin{array}{l}\text { Nielsen-Chen } \\
\text { model }\end{array}$ & $\begin{array}{l}\text { Computational } \\
\text { model }\end{array}$ & \\
\hline 1 & 0 & 76 & 76 & 76 & 76 & 0 \\
\hline 2 & 2.5 & 79 & 80.5 & 81 & 80 & 3.95 \\
\hline 3 & 5 & 84 & 90 & 85 & 84.5 & 10.53 \\
\hline 4 & 7.5 & 85 & 98 & 91 & 86 & 11.84 \\
\hline 5 & 10 & 87 & 109 & 95 & 87.5 & 14.47 \\
\hline
\end{tabular}

Table 4. Comparison of experimental and theoretical values of UTS of as cast Al 7075 alloy/basalt dispersed metal matrix composite.

\begin{tabular}{cccccc}
\hline \multirow{2}{*}{ Sl. No } & $\begin{array}{c}\text { Dispersoid basalt short } \\
\text { fiber content (\%) }\end{array}$ & $\begin{array}{c}\text { Experimental UTS } \\
\text { MPa }\end{array}$ & \multicolumn{2}{c}{ Theoretical UTS MPa } & Variation in the \\
\cline { 4 - 5 } & 0 & 129 & 129 & 128.29 & 0 \\
\hline 1 & 2.5 & 153 & 153 & 154.40 & 18.60 \\
2 & 5 & 169 & 177 & 171.91 & 31.00 \\
3 & 7.5 & 175 & 201 & 180.66 & 35.65 \\
4 & 10 & 179 & 225 & 180.89 & 38.75 \\
5
\end{tabular}

\subsection{Ductility}

The plot of ductility with a variation of basalt dispersoid in metal matrix composite has been presented in Figure 4. The measured mean values of ductility (\% of elongation) were plotted as a function of weight percentage of basalt short fiber.

From the study it can be observed that within the scope of this investigation as the short basalt fiber content was increased, there has been a decrease in the ductility. The plot of ductility with a variation of basalt dispersoid in metal matrix composite has been presented in Figure 4. The measured mean values of ductility (\% of elongation) were plotted as a function of weight percentage of basalt short fiber. It can be observed that up to $2.5 \%$ of dispersed basalt fiber addition there has been a decrease of 33.3\% in the young's modulus value. With further increase in addition of short basalt fiber, there has been monotonically and significant decrease in the ductility value and when short fiber content was $10 \%$ by wt., there has been an drop of $43.33 \%$ in ductility value. This decrease in ductility in comparison with the matrix alloy is a most commonly encountered disadvantage in dis- 


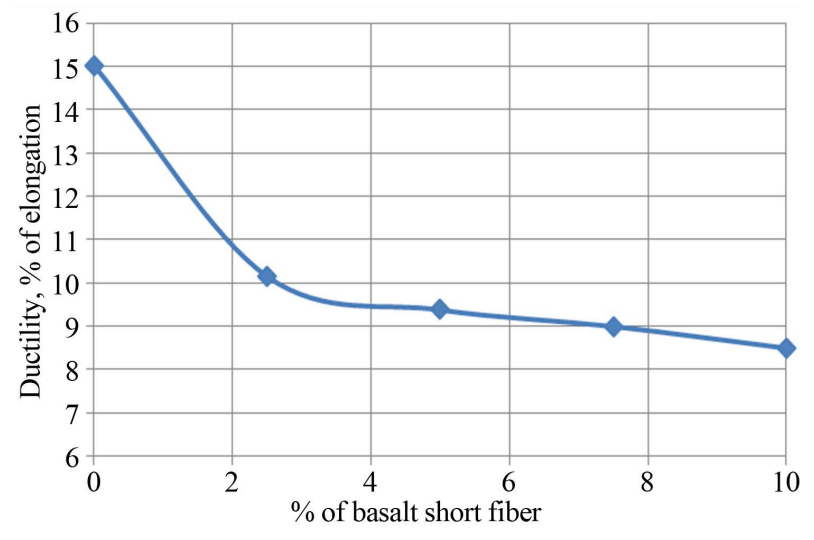

Figure 4. Effect \% of basalt short fiber on ductility of $\mathrm{Al} / \mathrm{ba}-$ salt short fiber composites.

continuously reinforced MMCs. These results tally with those obtained by other researchers [33]-[35] who also observed that the ductility of the composites decreases with increase in the reinforcement content. Mummery et al. [36] is of the opinion that this behaviour is probably due to the voids, which nucleate during the plastic strains of the reinforcement or by reinforcement interface.

\subsection{Hardness}

Hardness, which is described as a measure of a material's resistance to surface indentation, may be thought of as a function of the stress required to produce some specific types of surface deformation. The plot of Brinnel Hardness Number (BHN) with a variation of basalt dispersoid in metal matrix composite has been presented in Figure 5. The measured mean values of BHN were plotted as a function of weight percentage of basalt short fiber. From the study it can be observed that within the scope of this investigation as the basalt short fiber content was increased, there has been an increase in the hardness. It can be observed that up to $2.5 \%$ of dispersed basalt fiber addition there has been an increase of $9.2 \%$ in the BHN. The effect of wt\% reinforcement is more pronounced up to $7.5 \mathrm{wt} \%$ and after that it has a tendency to reduce the hardness due to agglomeration and casting defect. Maximum hardness of $19.84 \%$ is obtained at $7.5 \mathrm{wt} \%$ of basalt short fiber composites. With further increase in addition of basalt short fiber, there has been relative decrease in the BHN. The increase in hardness is probably attributed to the fact that the hard basalt fiber act as barriers to the movement of the dislocations within the matrix. Zhu and Liu [33] also observed a similar increase in hardness when ZA alloy is reinforced with short alumina fibres. Various other researchers have also reported that the addition of hard ceramic particulates or short fibres to metal alloys could lead to improved strength, wear resistance and hardness. A similar effect was observed by Sood et al. [34] for TiC reinforced aluminium alloy MMCs. They found that the hardness linearly increases with increasing volume percentage of TiC. Short basalt fiber, being hard exhibit a greater resistance to indentation by the hardness tester and hence enhanced hardness since the hardness, after all, it is a measure of the resistance of a material to surface indentation and is a function of the stress required to produce some specific type of surface deformation. The increased hardness is also attributed to the fact that the hard basalt fiber act as barriers to the movement of the dislocations within the matrix.

\subsection{Compression Strength}

The graph shown in the Figure 6, illustrates the effect of short basalt fiber reinforcement content on the compression strength of the composite. It is observed that the compressive strength of the composite is increased by about 11.98 percent as the reinforcement content increases from 0 to 2.5 weight percent. As the reinforcement content increases further, the compression strength of the composite increases from 11.98 to 41.66 percent. The results obtained in this study are inline with the other researchers [37] [38]. This increase in the compression strength is because of the presence of hard particles, which imparts high strength to the composite. This may be due to very small amounts of fibers at different orientations, which can make tremendous difference in stressstrain behavior. The rigidity and crushing strength of fiber is much higher than that of matrix material hence the strength increases. 


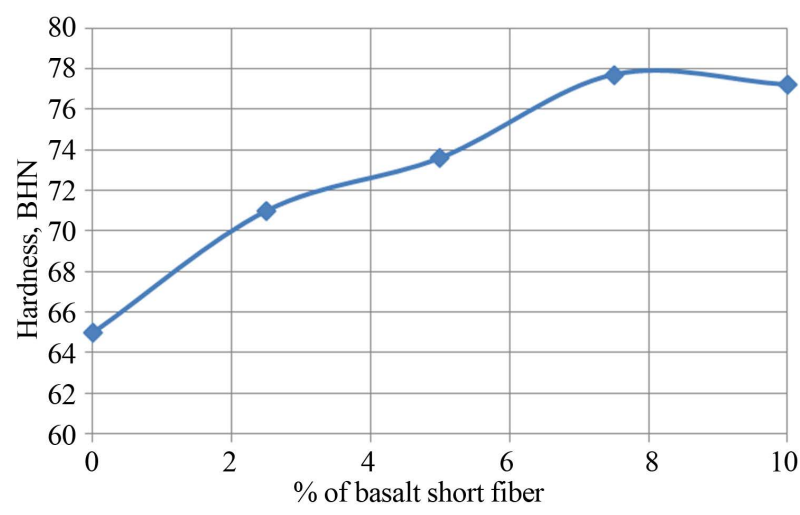

Figure 5. Effect \% of basalt short fiber on hardness of $\mathrm{Al} / \mathrm{ba}-$ salt short fiber composites.

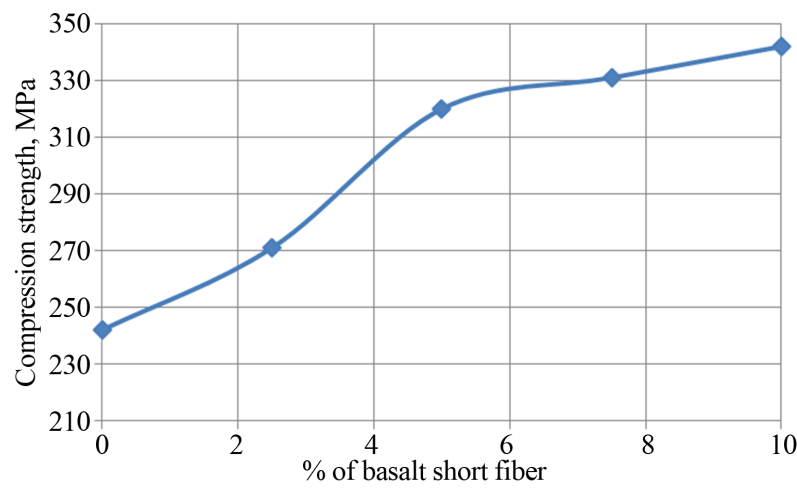

Figure 6. Effect\% of basalt short fiber on compression strength of $\mathrm{Al} /$ basalt short fiber composites.

\subsection{Fracture Studies}

During tensile test it is accepted that fiber cracking along with matrix material fracture and debonding between basalt fiber and $\mathrm{Al}$ matrix alloy interface are some of the reasons for failure MMCs. The ascast $\mathrm{Al}$ alloy fracture mode is a ductile fracture mode as shown in Figure 7(a-1). Which has large number of dimple shaped structures, no crack can be seen.

Figure 7(b-1) shows that as cast short basalt fiber reinforced MMCs fracture structures suffered from ductile failure which evidence by the extensive matrix deformation around the reinforcements is evident and matrix is necked to a knife edge between the fibers. The extensive matrix deformation around the fiber is evident, and the matrix is necked to a knife edge between the fibers. Also the interfacial region between the fiber and the matrix alloy appears discontinuous with a gap. However, the matrix alloy softens gradually, the critical fiber aspect ratio increase accordingly [39] [40]. Fracture surfaces of the test specimen of $\mathrm{Al}$ matrix alloy and $\mathrm{Al} / 10 \%$ basalt short fiber MMCs are shown in Figure 7(a-1) and Figure 7(b-1) respectively. The Al matrix alloy showed mixed mode failure i.e. the ductile and brittle failure. Along with dimples, some tear fracture can also seen in this microstructure. In Al/basalt fiber, MMCs showed that the main failure mechanisms were fiber debonding and matrix ductile failure, while only a small amount of cracked was observed. The fracture surfaces also displayed the presence of cracks, probably originated from casting defects or during cooling from the fabrication temperature.

\section{Conclusions}

The results of the investigation on the effect of short basalt fiber reinforcement content on mechanical properties of the $\mathrm{Al} 7075$ aluminium alloy composite, provide the following observations.

1) With increase in reinforcement content, there was substantial improvement in Young's modulus, UTS, 

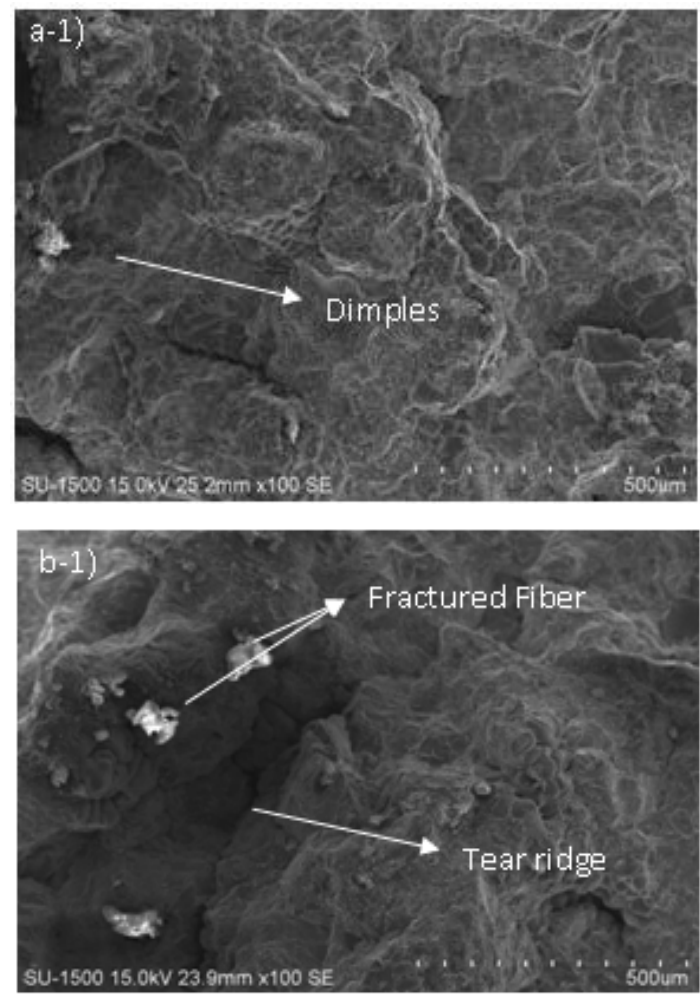

Figure 7. Fracture surfaces of samples tested for tensile test (a-1) Al matrix alloy and (b-1) $\mathrm{Al} / 10 \%$ basalt short fiber MMCs.

hardness and compression strength.

- The increase in Young's modulus is due to the hard basalt fiber, and may be probably of homogenous distribution of basalt short fiber and the alignment of basalt short fiber parallel to the axis with minimum segregation in the alloys, which was confirmed from the microstructural studies.

- The increase in UTS is attributed to the presence of hard basalt short fiber, which imparts strength to the matrix alloy, thereby providing enhanced tensile strength.

- The increase in hardness is probably attributed to the fact that the hard basalt fibers act as barriers to the movement of the dislocations within the matrix.

- This increase in the compression strength is because of the presence of hard particles, which imparts high strength to the composite.

2) With increase in reinforcement content ductility decreased substantially.

- The reduction in ductility can be attributed to the presence of a hard ceramic phase that is prone to localized crack initiation and increased embrittlement effect due to local stress concentration sites at the reinforcement matrix interface.

3) There has been a good agreement between the theoretical models prediction and the experimental results for Young's modulus and Ultimate tensile strength value of as cast Al 7075 alloy and basalt short fiber-reinforced composite.

4) The fracture was ductile with dimple surface showing fiber debonding, and fiber cracking.

\section{References}

[1] Ward, P.J., Atkinson, H.V., Anderson, P.R.G., Elias, L.G., Garcia, B., Kahlen, L. and Rodriguez-Ibabe, J.-M. (1996) Semi-Solid Processing of Novel MMCs Based on Hypereutectic Aluminium-Basal Short Fiber Alloys. Acta Materialia, 44, 1717-1727. http://dx.doi.org/10.1016/1359-6454(95)00356-8

[2] Ward-Close, C.M., Chandrasekaran, L., Robertson, J.G., Godfrey, S.P. and Murgatroyde, D.P. (1999) Advances in the Fabrication of Titanium Metal Matrix Composite. Materials Science and Engineering A, 263, 314-318. 
http://dx.doi.org/10.1016/S0921-5093(98)01162-9

[3] Kennedy, F.E., Balbahadur, A.C. and Lashmore, D.S. (1997) The Friction and Wear of Cu-Based Basal Short Fiber Carbide Particulate Metal Matrix Composites for Brake Applications. Wear, 203-204, 715-721. http://dx.doi.org/10.1016/S0043-1648(96)07451-0

[4] Akbulut, H., Durman, M. and Yilmaz, F. (1998) Dry Wear and Friction Properties of $\delta$ - $\mathrm{Al}_{2} \mathrm{O}_{3}$ Short Fiber Reinforced Al-Si (LM 13) Alloy Metal Matrix Composites. Wear, 215, 170-179. http://dx.doi.org/10.1016/S0043-1648(97)00237-8

[5] Gupta, N., Satyanarayana, K.G. and Materials, C. (2006) Symposium Review: Solidification Processing of MMCs. Journal of Materials Science, 58, 91-93.

[6] Miracle, D. (2005) Metal Matrix Composites-From Science to Technological Significance. Composites Science and Technology, 65, 2526-2540. http://dx.doi.org/10.1016/j.compscitech.2005.05.027

[7] Evans, A., Marchi, C. and Mortensen, A. (2003) Metal Matrix Composites in Industry: An Introduction and a Survey. Kluwer Academic Publisher, Dordrecht. http://dx.doi.org/10.1007/978-1-4615-0405-4

[8] Ibrahim, I.A., Mohamed, F.A. and Lavernia, E.J. (1991) Particulate Reinforced Metal Matrix Composites. Journal of Materials Science, 26, 1137-1156. http://dx.doi.org/10.1007/BF00544448

[9] Chou, T.W., Kelly, A. and Okurat, A. (1985) Composites de Matrices en Métal Renforcés aux Fibres. Composites, 16, 183-184. http://dx.doi.org/10.1016/0010-4361(85)90603-2

[10] Kelly, A., Fishman, S. and Dhingra, A. (1988) Metal Matrix Composite, A Review. Proceeding International Symposium on Advances in Cast Reinforced Metal Composite, Chicago.

[11] Wessel, J.K. (2004) The Handbook of Advanced Materials. John Wiley \& Sons Inc., New Jersey. http://dx.doi.org/10.1002/0471465186

[12] Everett, R.K. and Arsenault, R.J. (1991) Metal Matrix Composites: Mechanisms and Properties. Academic Press, San Diego.

[13] Kocjak, M.J., Kahtri, S.C., Allison, J.E. and Jones, J.W. (1993) Fundamentals of Metal Matrix Composites. Butterworth-Heinemann, Boston.

[14] Pai, B.C., Ray, S., Prabhakar, K.V. and Rohatgi, P.K. (1976) Fabrication of Aluminiumalumina (Magnesia) Particulate Composites in Foundries Using Magnesium Additions to the Melts. Materials Science and Engineering, 24, 31. http://dx.doi.org/10.1016/0025-5416(76)90092-6

[15] (1996) ASM Handbook, Casting, Vol. 15, ASM International.

[16] Sato, A. and Mehrabian, R. (1976) Aluminum Matrix Composites: Fabrication and Properties. Metallurgical Transactions B, 7, 443-451. http://dx.doi.org/10.1007/BF02652716

[17] Awerbuch, J., Goering, J. and Busking, K. (1988) In Mini Mechanics Analysis and Testing of Short Fibre Composites: Experimental Methods and Results, Vol. 121. American Society for Testing and Materials, Philadelphia, 964.

[18] Smith, W.F. (1993) Structure and Properties of Engineering Alloys. 2nd Edition, McGraw-Hill, New York, 566.

[19] Pillai, U.T.S. and Pandey, R.K. (1989) Studies on Mechanical Behaviour of Cast and Forged Al-Graphite Particle Composites. Journal of Composite Materials, 23, 108-132. http://dx.doi.org/10.1177/002199838902300201

[20] Li, G., Ponte Castaneda, P. and Douglas, A.S. (1993) Constitutive Models for Ductile Solids Reinforced by Rigid Spheroidal Inclusions. Mechanics of Materials, 15, 279-300. http://dx.doi.org/10.1016/0167-6636(93)90004-B

[21] Li, J. and Weng, G.J. (1998) A Unified Approach from Elasticity to Viscoelasticity to Viscoplasticity of Particle-Reinforced Solids. International Journal of Plasticity, 14, 193-208. http://dx.doi.org/10.1016/S0749-6419(97)00048-X

[22] Zhu, H.T. and Zbib, H.M. (1995) A Macroscopic Model for Plastic Flow in Metal-Matrix Composites. International Journal of Plasticity, 11, 471-499. http://dx.doi.org/10.1016/S0749-6419(95)00009-7

[23] Kailasam, M. and Ponte Castaneda, P. (1998) A General Constitutive Theory for Linear and Nonlinear Particulate Media with Microstructure Evolution. Journal of the Mechanics and Physics of Solids, 46, 427-465. http://dx.doi.org/10.1016/S0022-5096(97)00095-1

[24] Eshelby, J.D. (1961) Elastic Inclusions and Inhomogeneities. Progress in Solid Mechanics, 2, 89-140.

[25] Taya, M. (1981) On Stiffness and Strength of an Aligned Short-Fiber Reinforced Composite Containing Penny-Shaped Cracks in the Matrix. Journal of Composite Materials, 15, 198-210. http://dx.doi.org/10.1177/002199838101500301

[26] Mori, T. and Tanaka, K. (1973) Average Stress in Matrix and Average Elastic Energy of Materials with Misfitting Inclusions. Acta Metallurgica, 21, 571-574. http://dx.doi.org/10.1016/0001-6160(73)90064-3

[27] Taya, M. and Arsenault, R.J. (1989) Metal Matrix Composites. Pergamon, New York.

[28] Llorca, J. and GonAllez, C. (1998) Microstructural Factors Controlling the Strength and Ductility of Particle-Rein- 
forced Metal-Matrix Composites. Journal of the Mechanics and Physics of Solids, 46, 1-28. http://dx.doi.org/10.1016/S0022-5096(97)00038-0

[29] Shu, J.Y. and Barlow, C.Y. (2000) Strain Gradient Effects on Microscopic Strain Field in a Metal Matrix Composite. International Journal of Plasticity, 16, 563-591. http://dx.doi.org/10.1016/S0749-6419(99)00088-1

[30] Seah, K.H.W., Sharma, S.C. and Girish, B.M. (1995) Mechanical Properties of Cast ZA-27/Graphite Particulate Composites. Materials and Design, 16, 271-275. http://dx.doi.org/10.1016/0261-3069(96)00001-5

[31] McDanels, D.L. (1985) Analysis of Stress-Strain, Fracture, and Ductility Behavior of Aluminum Matrix Composites Containing Discontinuous Basalt Short Fiber Carbide Reinforcement. Metallurgical Transactions A, 16, 1105-1115. http://dx.doi.org/10.1007/BF02811679

[32] Vogelsang, M., Arsenault, R.J. and Fisher, R.M. (1986) An in Situ HVEM Study of Dislocation Generation at Al/SiC Interfaces. Metallurgical Transactions A, 17, 379-389. http://dx.doi.org/10.1007/BF02643944

[33] Zhu, H.X. and Liu, S.K. (1993) Mechanical Properties of Squeeze Cast Zinc Alloy Matrix Composites Containing $\alpha$ Alumina Fibers. Composites, 24, 437-442. http://dx.doi.org/10.1016/0010-4361(93)90251-3

[34] Sood, J., Tiwari, A.N. and Teredesai, A. (1991) TiC-Reinforced Al Matrix Composites. In: Proceedings of 2nd International Conference on Aluminium INCAL-91, Aluminium Association, Bangalore, 31 July-2 August 1991, 781-785.

[35] Sanders, B.R. and Weintraub, T.L. (1995) ASM Handbook, Vol. 8, Mechanical Testing. American Society of Metals, Philadelphia, 84.

[36] Mummery, P.M., Derby, B. and Scruby, C.B. (1993) Acoustic Emission from Particulate Reinforced Metal Matrix Composites. Acta Metallurgica et Materialia, 41, 1431-1445. http://dx.doi.org/10.1016/0956-7151(93)90252-N

[37] Seah, K.H.W., Sharma, S.C. and Ramesh, A. (2000) Mechanical Properties of Cast Aluminium Alloy 6061-Albite Particulate Composites. Proceedings of the Institution of Mechanical Engineers, Part L, 214, 1-6.

[38] Sharma, S.C., Girish, B.M., Kamath, R. and Satish, B.M. (1999) Fractography, Fluidity, and Tensile Properties of Aluminum/Hematite Particulate Composites. Journal of Materials Engineering and Performance, 8, 309-314.

[39] See, K.S. and Dean, T.A. (1997) The Effects of the Disposition of SiC Particles on the Forgeability and Mechanical Properties of Co-Sprayed Aluminium-Based MMCs. Journal of Materials Processing Technology, 69, 58-67.

[40] See, K.S. and Dean, T.A. (1997) The Effects of Pre-Forge Processing on Forgeability and Mechanical Properties of Co-Sprayed Aluminium-Based MMCs. Journal of Materials Processing Technology, 71, 314-321. 